\title{
Update on the diagnosis and management of Parkinson's disease
}

\author{
Author: Christopher Kobylecki ${ }^{\mathrm{A}}$
}

Parkinson's disease (PD) is diagnosed where bradykinesia occurs together with rigidity or tremor, in the presence of supporting features. The diagnosis is clinical, and attention should be paid to exclusion criteria indicating an alternative diagnosis and to 'red flag' features. There is no cure or diseasemodifying treatment for PD, and the rate of progression is variable. The most effective symptomatic treatment remains levodopa, which has superior benefits for quality of life in early PD compared to other therapies. Motor fluctuations and dyskinesia later in the disease course can be improved with adjunctive treatments. Around $10 \%$ of patients per year with refractory motor fluctuations may be eligible for advanced therapies, including deep-brain stimulation surgery. There is emerging evidence for the management of non-motor symptoms in PD, and the importance of multidisciplinary care. In this article, the evidence base for optimal diagnosis and management of PD is discussed.

\section{Introduction}

Parkinson's disease (PD) is the second most common neurodegenerative disorder. Its global prevalence is projected to double by 2040 , due partly to an ageing population. ${ }^{1}$ In the UK, 137,000 people were estimated to be living with PD in 2015 , around $60 \%$ of whom were male; over 17,000 people are diagnosed with PD yearly. ${ }^{2}$ Although incidence increases with age, symptom onset is before the age of 40 years in around $5 \%$ of patients. Dopamine denervation due to Lewy body deposition and cell death in the substantia nigra is the primary neuropathology, but a large number of extra-nigral and non-dopaminergic brain regions are also affected.

\section{Diagnosis of Parkinson's disease}

The diagnosis of PD is clinical and requires bradykinesia, defined as 'slowness of movement and decrement in amplitude or speed', usually assessed using finger tapping, foot tapping or pronationsupination hand movements. ${ }^{3}$ In addition, rest tremor or rigidity is

Author: ${ }^{A}$ consultant neurologist and honorary senior lecturer, Manchester Centre for Clinical Neurosciences, Salford, UK and University of Manchester, Manchester, UK required to confirm a parkinsonian syndrome. Tremor was absent at presentation in $30 \%$ in one series of pathologically proven PD. ${ }^{4}$ Patients with suspected PD should be referred quickly and untreated to a specialist in movement disorders for evaluation. ${ }^{5}$ Key points for discussion at diagnosis include the need to inform vehicle licensing agencies and insurers, signposting to written or web-based information on newly diagnosed PD, and provision of contact details for the local PD nurse specialist (PDNS). ${ }^{5}$

Post-mortem studies of clinically diagnosed PD show an overall diagnostic accuracy of $81 \%$, indicating the need to re-appraise the clinical diagnosis regularly. ${ }^{6}$ The presence of exclusionary features (Table 1) indicates possible alternative diagnoses and allows one confidently to exclude PD. Several 'red flag' features should also prompt re-appraisal of the diagnosis. ${ }^{3}$ The most common causes of PD misdiagnosis are atypical parkinsonian syndromes, including multiple system atrophy (MSA) and progressive supranuclear palsy (PSP). These conditions generally have a more aggressive disease

\section{Key points}

The diagnosis of Parkinson's disease is clinical and should be regularly reviewed during follow-up for 'red flag' features.

Levodopa is the most effective symptomatic treatment and improves quality of life compared to other therapies.

Patients must be counselled about the risk of impulse control disorder when taking dopaminergic therapy, especially dopamine agonists.

Consider referral for advanced therapies where uncontrolled motor fluctuations and dyskinesia persist despite optimised oral therapy.

Multidisciplinary team input and effective management of non-motor symptoms are important at all stages of Parkinson's disease.

KEYWORDS: Parkinson's disease, diagnosis, levodopa, treatment, non-motor symptoms

DOI: $10.7861 /$ clinmed.2020-0220 
Table 1. Current International Parkinson and Movement Disorder Society diagnostic criteria for Parkinson's disease; adapted from Postuma RB, Berg D, Stern M et al. MDS clinical diagnostic criteria for Parkinson's disease. Mov Disord 2015;30:1591-601. At least two supportive criteria and no red flags required for a diagnosis of 'clinically established Parkinson's disease'. Conditions in italics should be considered if the corresponding exclusion criteria or red flags are present.

Parkinsonism defined as: Bradykinesia and rest tremor and/or rigidity

Supportive criteria

Clear and dramatic response to dopaminergic therapy

Levodopa-induced dyskinesia

Limb rest tremor

Olfactory loss

Abnormal MIBG SPECT
Exclusion criteria: PD excluded if present

\section{Alternative diagnosis}

Cerebellar signs

MSA

Downward vertical supranuclear gaze palsy or slow downward saccades

PSP

Behavioural variant FTD or progressive aphasia within 5 years

FTD, PSP

Lower limb signs only for $>3$ years

$V P, N P H$

Treatment with dopamine receptor antagonists

Drug-induced parkinsonism

Absence of observable response to high dose levodopa (>600 mg/day)

MSA, PSP, CBD

Cortical sensory loss, apraxia, progressive aphasia $C B D, A D$

Normal dopaminergic functional imaging (eg dopamine transporter SPECT)

Non-degenerative eg essential tremor, dystonic tremor, drug-induced

\section{Red flags}

\section{Possible alternative diagnosis}

Wheelchair use within 5 years of onset MSA, PSP

Absent progression over 5 years

Non-degenerative eg essential tremor, dystonic tremor, drug-induced

Early severe dysphonia, dysarthria, dysphagia MSA, PSP

Inspiratory stridor

MSA

Severe autonomic failure within 5 years MSA

Recurrent falls within 3 years

PSP

Disproportionate antecollis (excessive forward neck flexion) or limb contractures within 10 years MSA

Absence of any non-motor features after 5 years Non-degenerative

Otherwise unexplained pyramidal signs

MSA, VP

Symmetrical parkinsonism throughout disease course

Atypical parkinsonism

$\mathrm{AD}=$ Alzheimer's disease; $\mathrm{CBD}$ = corticobasal degeneration; FTD = frontotemporal dementia; $\mathrm{MIBG}$ = metaiodobenzylguanidine; MSA = multiple system atrophy; $\mathrm{NPH}=$ normal pressure hydrocephalus; $\mathrm{PD}=$ Parkinson's disease; $\mathrm{PSP}=$ progressive supranuclear palsy; $\mathrm{SPECT}$ = single-photon emission computed tomography: $\mathrm{VP}=$ vascular parkinsonism.

course and poorer response to dopaminergic treatment compared to PD, but may present initially in a similar manner. In young people presenting with parkinsonism, a wider range of causes, including monogenic forms of parkinsonism and reversible causes such as Wilson's disease, need also to be considered.

Where postural tremor is the main feature, an important differential diagnosis is essential or dystonic tremor. Dopaminetransporter single-photon emission computed tomography can be useful to distinguish PD from such tremor syndromes, but is not sufficiently accurate to differentiate other degenerative parkinsonian syndromes. ${ }^{5}$ Structural magnetic resonance imaging (MRI) of the brain is useful where MSA or PSP are considered, showing specific patterns of focal atrophy, and may also help interpretation of dopaminergic imaging where pre-existing lesions can cause difficulties in interpretation.?

\section{Progression of Parkinson's disease}

The disease progression of PD from diagnosis has been conceptualised into four stages (Fig 1). ${ }^{8}$ It is also important to recognise a prodromal phase in which non-motor symptoms, such as anosmia, constipation and rapid-eye-movement (REM) sleep behaviour disorder may predict the development of motor PD. Motor complications are more common as PD progresses, and typify transition to the complex phase. Many so-called 'axial' symptoms of later stage PD, such as dysphagia, gait disturbance 


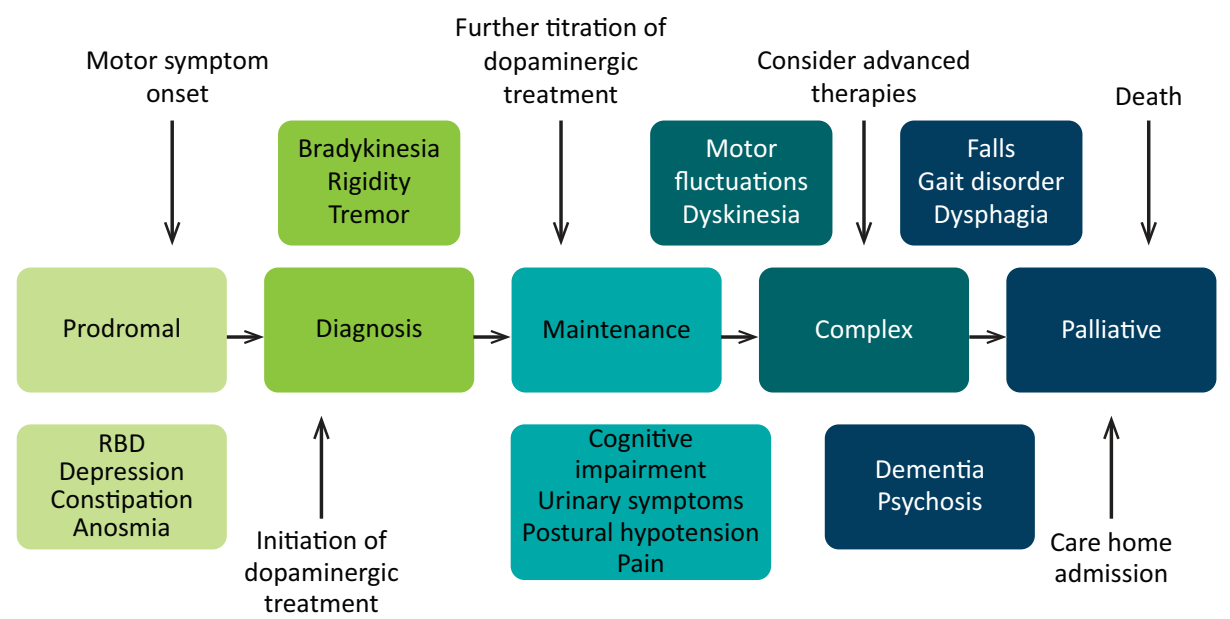

Fig 1. Stages of Parkinson's disease. $\mathrm{RBD}=$ rapid eye movement sleep behaviour disorder. and falls, do not respond to levodopa, but may be helped by multidisciplinary team input. Dementia occurs in up to $80 \%$ of people with PD after 20 years' disease duration. ${ }^{9}$ The rate of PD progression is heterogeneous and is generally more rapid in those with older age and more severe motor impairment at onset. ${ }^{10}$

\section{Pharmacological treatment of Parkinson's disease}

There is currently no proven disease-modifying or neuroprotective therapy for PD. ${ }^{11}$ A summary of previous neuroprotection trials is given in a recent review article. ${ }^{12}$ Current evidence-based treatment for PD is symptomatic and mainly based around dopaminergic replacement or modulation (Table 2). The evidence base is summarised in recent guidelines from the National Institute for Health and Care Excellence (NICE) and the International Parkinson and Movement Disorder Society. 5,11 Levodopa, dopamine agonists and monoamine oxidase $B$ inhibitors (MAOB-I) are all licensed for use as initial therapy in PD. Anticholinergics are no longer routinely used due to the risk of cognitive decompensation. $^{5}$

\section{Starting treatment in early Parkinson's disease}

The optimal time to start treatment in PD has been the source of much debate. In an open-label study of 198 patients with untreated PD, quality of life (QoL) as measured by the Parkinson's Disease Questionnaire-39 (PDQ-39) worsened in those left untreated, but was stable or improved in patients receiving dopaminergic treatment. ${ }^{13}$ In an observational study comparing Italian patients with PD who started levodopa early with those in Ghana where therapy was delayed, motor fluctuations and dyskinesia occurred at similar disease duration. ${ }^{14}$ This showed that duration of disease rather than treatment is a key determinant of motor complications. Therefore, delaying dopaminergic therapy does not avoid the development of motor complications and may be associated with poorer QoL. The recent delayed-start LEAP study showed no disease-modifying effect of levodopa in patients diagnosed $<2$ years prior, but PDQ-39 score was improved in the blinded phase in those receiving early vs delayed treatment. ${ }^{15}$

Concerns about the development of motor complications with levodopa led to a 'levodopa-sparing' approach by many physicians treating PD. The PD-MED study randomised 1,620 patients with early PD to either levodopa or 'levodopa-sparing' therapy (dopamine agonist or MAOB-I) with a median follow-up of 3 years. The mobility score of the PDQ-39 and overall QoL was improved in those treated with levodopa vs levodopa-sparing therapy. More patients stopped treatment in the levodopasparing group, with $28 \%$ on dopamine agonists and $23 \%$ on MAOI-B stopping due to adverse effects compared to just $2 \%$ on levodopa. ${ }^{16}$ While dyskinesia occurred earlier in those started on levodopa, there was no difference in motor fluctuations. Accordingly, current NICE guidance is to 'offer levodopa to people in the early stages of PD whose motor symptoms impact on their quality of life'. ${ }^{5}$ A recent review of treatment strategies in early PD summarises the evidence in detail. ${ }^{12}$

The increasing recognition of impulse-control disorders (ICD) has also altered perceptions of the risk profile of dopamine agonists. ICDs include pathological gambling, hypersexuality, and compulsive shopping and eating; occur in around $14 \%$ of patients with PD; and are 2-3 times more common in those taking dopamine agonists. ${ }^{17}$ Recent data suggest that ICD may occur in over $40 \%$ of people with PD after 5 years of dopamine agonist treatment, with a relationship to agonist dose and treatment duration. ${ }^{18}$ Stopping dopamine agonists in patients with ICD may also lead to problematic withdrawal symptoms. Discussing these potentially serious complications should be part of shared decision-making when agreeing treatments for PD.

\section{Adjunctive therapies in Parkinson's disease}

Adjunctive therapies are used to treat motor complications in PD. Wearing-off, in which motor benefit decreases before the next levodopa dose is due, and delayed-on periods are the most common motor fluctuations, but sudden or unpredictable offperiods can also occur. ${ }^{19}$ Levodopa-induced dyskinesia, involuntary choreiform or dystonic movements, typically worst at peak motor benefit, may also cause significant disability. The addition of dopamine agonists, MAOB-I or catechol-O-methyltransferase (COMT) inhibitors to a levodopa-based regimen have all been shown to reduce off-time and improve on-time, although all may result in more dyskinesia (Table 2$).{ }^{11}$ Amantadine is the main oral treatment for dyskinesia. 
Table 2. Pharmacological therapies currently used for initial and adjunctive treatment of motor symptoms in Parkinson's disease

\begin{tabular}{|c|c|c|c|c|c|}
\hline Class & Drugs & Indication & Motor benefit & Common adverse effects & Comments \\
\hline $\begin{array}{l}\text { Levodopa } \\
\text { (with dopa- } \\
\text { decarboxylase } \\
\text { inhibitor) }\end{array}$ & $\begin{array}{l}\text { Levodopa }+ \\
\text { carbidopa } \\
\text { (co-careldopa) } \\
\text { Levodopa }+ \\
\text { benserazide } \\
\text { (co-beneldopa) }\end{array}$ & Initial therapy & +++ & $\begin{array}{l}\text { Motor fluctuations } \\
\text { Dyskinesia }\end{array}$ & $\begin{array}{l}\text { CR preparation } \\
\text { only routinely } \\
\text { used at night, } \\
\text { immediate release } \\
\text { preparation during } \\
\text { the day }\end{array}$ \\
\hline Dopamine agonist & $\begin{array}{l}\text { Pramipexole } \\
\text { Ropinirole } \\
\text { Rotigotine (skin } \\
\text { patch) }\end{array}$ & Initial/adjunctive & ++ & $\begin{array}{l}\text { Nausea } \\
\text { Drowsiness } \\
\text { Hallucinations } \\
\text { Ankle oedema } \\
\text { Postural hypotension } \\
\text { Impulse control disorder }\end{array}$ & $\begin{array}{l}\text { All available } \\
\text { as once-daily } \\
\text { preparation }\end{array}$ \\
\hline & $\begin{array}{l}\text { Apomorphine } \\
\text { pen (sub- } \\
\text { cutaneous) }\end{array}$ & $\begin{array}{l}\text { Rescue therapy for } \\
\text { off periods }\end{array}$ & +++ & $\begin{array}{l}\text { Nausea } \\
\text { Drowsiness } \\
\text { Hallucinations } \\
\text { Ankle oedema } \\
\text { Postural hypotension } \\
\text { Impulse control disorder }\end{array}$ & $\begin{array}{l}\text { Rapid onset } \\
\text { shorter duration of } \\
\text { action } \\
\text { Skin nodules }\end{array}$ \\
\hline $\begin{array}{l}\text { Monoamine } \\
\text { oxidase inhibitor } \\
\text { (reduces central } \\
\text { dopamine } \\
\text { catabolism) }\end{array}$ & $\begin{array}{l}\text { Selegiline } \\
\text { Rasagiline } \\
\text { Safinamide }^{a}\end{array}$ & $\begin{array}{l}\text { Initial/adjunctive } \\
\text { Initial/adjunctive } \\
\text { Adjunctive }\end{array}$ & $\begin{array}{l}+ \\
\text { Improved wearing-off } \\
\text { Improved wearing-off }\end{array}$ & $\begin{array}{l}\text { Mood changes } \\
\text { Dry mouth } \\
\text { Dyskinesia }\end{array}$ & $\begin{array}{l}\text { Once daily } \\
\text { Once daily } \\
\text { Once daily }\end{array}$ \\
\hline $\begin{array}{l}\text { COMT inhibitor } \\
\text { (inhibit peripheral } \\
\text { levodopa } \\
\text { catabolism) }\end{array}$ & Entacapone & Adjunctive & Improved wearing-off & $\begin{array}{l}\text { Diarrhoea } \\
\text { Dyskinesia }\end{array}$ & $\begin{array}{l}\text { With each } \\
\text { levodopa dose } \\
\text { or as combined } \\
\text { preparation }\end{array}$ \\
\hline & Opicapone & Adjunctive & Improved wearing-off & Dyskinesia & Once daily \\
\hline & Tolcapone & Adjunctive & Improved wearing-off & $\begin{array}{l}\text { Dyskinesia } \\
\text { Hepatotoxicity }\end{array}$ & Three times daily \\
\hline NMDAR antagonist & Amantadine & Adjunctive & Improved dyskinesia & $\begin{array}{l}\text { Skin rash } \\
\text { Ankle oedema } \\
\text { Hallucinations }\end{array}$ & \\
\hline
\end{tabular}

${ }^{a}=$ combined monoamine oxidase and sodium channel/glutamate release inhibitor; COMT = catechol-O-methyltransferase; $C R=$ controlled release; NMDAR = $\mathrm{N}$-methyl-D-aspartate receptor. Motor benefit: $+++=$ excellent; $++=$ good; $+=$ fair.

Two newer adjunctive therapies have recently been licensed. The once-daily COMT inhibitor opicapone has shown significant reductions in off-time vs placebo, and non-inferiority to entacapone. ${ }^{20}$ Safinamide, a combined MAOB-I and glutamate release inhibitor, improved on-time compared to placebo, although proposed anti-dyskinetic effects were only observed in a subgroup with more severe baseline dyskinesia. ${ }^{21}$

\section{Advanced therapies for Parkinson's disease}

When significant off-time or dyskinesia persists despite optimised oral treatment, advanced therapies should be considered. Apomorphine, a potent dopamine agonist given by continuous subcutaneous infusion, is the least invasive and most straightforward of these. Following on from extensive clinical experience, the recent double-blind TOLEDO study confirmed a significant reduction in off-time and improved on-time with apomorphine versus placebo. ${ }^{22}$

Deep-brain stimulation (DBS) involves surgical placement of electrodes into brain regions such as the subthalamic nucleus to improve motor fluctuations or refractory tremor. DBS is typically considered in patients without significant axial or neuropsychiatric problems. It improves motor function, off-time and QoL in patients with PD, and provides significant benefits over medical therapy even in patients with an average disease duration of 7 years. ${ }^{11,23}$ The benefits of DBS on motor function, fluctuations and 
Table 3. Summary of evidence for management of common non-motor symptoms of Parkinson's disease

\begin{tabular}{|c|c|c|c|c|}
\hline Symptom & Therapy & $\begin{array}{l}\text { NICE } \\
\text { guidelines }\end{array}$ & $\begin{array}{l}\text { MDS EBM } \\
\text { review }^{27}\end{array}$ & Comments \\
\hline \multirow[t]{3}{*}{ Depression } & Pramipexole & \multirow[t]{3}{*}{$\mathrm{n} / \mathrm{a}$} & \multirow[t]{3}{*}{+} & Optimise dopaminergic therapy \\
\hline & Consider antidepressant & & & \multirow[t]{2}{*}{ SSRIs and venlafaxine effective } \\
\hline & CBT & & & \\
\hline Dementia & $\begin{array}{l}\text { Cholinesterase inhibitor eg } \\
\text { rivastigmine }\end{array}$ & + & + & May worsen tremor, GI/bladder AEs \\
\hline \multirow[t]{2}{*}{ Psychosis } & Quetiapine & + & + & Usually first line \\
\hline & Clozapine & + & + & Requires FBC monitoring \\
\hline \multirow[t]{2}{*}{ Postural hypotension } & Midodrine & \multirow[t]{2}{*}{+} & \multirow[t]{2}{*}{$+1-$} & \multirow{2}{*}{$\begin{array}{l}\text { Reduce anti-hypertensives and other } \\
\text { potential exacerbating drugs }\end{array}$} \\
\hline & Fludrocortisone & & & \\
\hline \multirow[t]{3}{*}{ Constipation } & Macrogol & \multirow[t]{3}{*}{$\mathrm{n} / \mathrm{a}$} & $+1-$ & Ensure good hydration \\
\hline & Lubiprostone & & $+1-$ & \multirow{2}{*}{$\begin{array}{l}\text { Constipation may impact on medication } \\
\text { absorption }\end{array}$} \\
\hline & Probiotics and prebiotic fibre & & + & \\
\hline \multirow[t]{2}{*}{ Drooling } & Glycopyrronium & + & + & \multirow[t]{2}{*}{ Anticholinergics may cause cognitive AEs } \\
\hline & BoNT injection to salivary glands & + & + & \\
\hline \multirow[t]{2}{*}{ Nocturnal akinesia } & Levodopa CR & \multirow[t]{2}{*}{+} & \multirow[t]{2}{*}{+} & \\
\hline & Rotigotine & & & \\
\hline \multirow{2}{*}{$\begin{array}{l}\text { REM sleep behaviour } \\
\text { disorder }\end{array}$} & Clonazepam & \multirow[t]{2}{*}{+} & \multirow[t]{2}{*}{$\mathrm{n} / \mathrm{a}$} & \\
\hline & Melatonin & & & \\
\hline
\end{tabular}

+ = recommended by guidance; $+/-$ = possibly useful or evidence insufficient; $\mathrm{AE}=$ adverse effect; BoNT = botulinum neurotoxin; CBT = cognitive-behavioural therapy; $\mathrm{CR}=$ controlled release; $\mathrm{FBC}=$ full blood count; $\mathrm{GI}=$ gastrointestinal; $\mathrm{MDS}=$ International Parkinson and Movement Disorder Society; $\mathrm{n} / \mathrm{a}=$ no recommendation; NICE = National Institute for Health and Care Excellence; REM = rapid eye movement; SSRIs = selective serotonin reuptake inhibitors.

activities of daily living have been demonstrated up to 10 years postoperatively, although axial features continue to progress. ${ }^{24}$ Infusion of levodopa-carbidopa intestinal gel via jejunostomy has also been shown to improve off-time compared to oral levodopa, and is commissioned in specialist centres where other advanced therapies are ineffective or contraindicated. ${ }^{25}$ Further information on the decision-making process for advanced therapies is summarised in a dedicated review. ${ }^{26}$

\section{Non-motor symptoms in Parkinson's disease}

Non-motor symptoms such as depression, constipation and REM sleep behaviour disorder, are increasingly recognised and may precede the diagnosis of PD by many years. Non-motor fluctuations are well recognised and some may improve with optimisation of dopaminergic therapies to improve wearingoff. ${ }^{19}$ Many non-motor symptoms have a non-dopaminergic or extra-nigral origin. Table 3 summarises the evidence base for management of some common non-motor symptoms, based on recent published guidance. ${ }^{5,27}$

\section{Non-pharmacological management}

Exercise is increasingly recognised as important in PD

management. A recent randomised controlled trial in 130 patients with early PD showed a significant improvement in off-state motor severity following 6 months of home-based aerobic exercise, compared with controls. ${ }^{28}$ The long-term effects need to be further investigated. Current NICE guidelines recommend that all people with PD should have access to a PDNS. ${ }^{5}$ In addition, specialist physiotherapy, speech and language therapy, and occupational therapy referrals should be made for people experiencing difficulties with gait/falls, communication/swallowing and activities of daily living, respectively. ${ }^{5}$ Palliative care services have increasing importance in the palliative stage of PD and end-of-life care, but may be helpful in establishing care plans at any stage of PD. ${ }^{5}$

\section{Inpatient management of Parkinson's disease}

Patients with PD are often admitted to hospital for other reasons, but the unique challenges of the condition mean that outcomes related to PD are often suboptimal. Many hospitals have an alert system to inform members of the PD team of admission to allow proactive in-reach consultations. It is essential that antiparkinsonian medications are given on time and in correct dosage, as sudden reduction or withdrawal of medication can lead to severe morbidity or even mortality due to parkinsonismhyperpyrexia syndrome. Dopamine blocking drugs must not be given. When patients with PD cannot take their usual oral medications, we recommend that an equivalent dosage be given via nasogastric tube. If this is not possible, or enteral medication is contraindicated, cautious use of rotigotine patch can be helpful. ${ }^{29}$ 


\section{Conclusions}

The diagnosis of PD remains clinical, and close attention and review for features indicating an alternative diagnosis is key given the absence of a definitive diagnostic test. Levodopa remains the most effective therapy for motor symptoms of PD, but individualised therapy is important given the heterogeneity of progression of motor and non-motor features. It is important to recognise and manage the non-motor symptoms of PD effectively, and to consider potential candidates for advanced therapies. Lastly, targeted multidisciplinary care is crucial to effective management of this complex condition.

\section{Conflicts of interest}

Dr Kobylecki has received honoraria from Bial Pharma, Britannia Pharmaceuticals and Abbvie outside of the submitted work.

\section{References}

1 Dorsey ER, Sherer T, Okun MS, Bloem BR. The emerging evidence of the parkinson pandemic. J Parkinsons Dis 2018;8:S3-8.

2 Parkinson's UK. The incidence and prevalence of Parkinson's in the UK report. Parkinson's UK, 2017.

3 Postuma RB, Berg D, Stern M et al. MDS clinical diagnostic criteria for Parkinson's disease. Mov Disord 2015;30:1591-601.

4 Hughes AJ, Daniel SE, Blankson S, Lees AJ. A clinicopathologic study of 100 cases of Parkinson's disease. Arch Neurol 1993;50:140-8.

5 National Institute for Health and Care Excellence. Parkinson's disease in adults: diagnosis and management: NICE guideline [NG71]. NICE, 2017.

6 Rizzo G, Copetti M, Arcuti S et al. Accuracy of clinical diagnosis of Parkinson disease: A systematic review and meta-analysis. Neurology 2016:86:566-76.

7 Massey LA, Micallef C, Paviour DC et al. Conventional magnetic resonance imaging in confirmed progressive supranuclear palsy and multiple system atrophy. Mov Disord 2012;27:1754-62.

8 MacMahon DG, Thomas S. Practical approach to quality of life in Parkinson's disease: the nurse's role. J Neurol 1998;245(Suppl 1): S19-22.

9 Hely MA, Reid WG, Adena MA, Halliday GM, Morris JG. The Sydney multicenter study of Parkinson's disease: the inevitability of dementia at 20 years. Mov Disord 2008;23:837-44.

10 De Pablo-Fernandez E, Lees AJ, Holton JL, Warner TT. Prognosis and Neuropathologic correlation of clinical subtypes of Parkinson disease. JAMA Neurol 2019;76:470-9.

11 Fox SH, Katzenschlager R, Lim SY et al. International Parkinson and movement disorder society evidence-based medicine review: Update on treatments for the motor symptoms of Parkinson's disease. Mov Disord 2018;33:1248-66.

12 de Bie RMA, Clarke CE, Espay AJ, Fox SH, Lang AE. Initiation of pharmacological therapy in Parkinson's disease: when, why, and how. Lancet Neurol 2020;19:452-61.

13 Grosset D, Taurah L, Burn DJ et al. A multicentre longitudinal observational study of changes in self reported health status in people with Parkinson's disease left untreated at diagnosis. J Neurol Neurosurg Psychiatry 2007;78:465-9.

14 Cilia R, Akpalu A, Sarfo FS et al. The modern pre-levodopa era of Parkinson's disease: insights into motor complications from subSaharan Africa. Brain 2014;137:2731-42.
15 Verschuur CVM, Suwijn SR, Boel JA et al. Randomized delayedstart trial of levodopa in Parkinson's disease. N Engl J Med 2019;380:315-24.

16 PD MED Collaborative Group, Gray R, Ives N et al. Long-term effectiveness of dopamine agonists and monoamine oxidase $\mathrm{B}$ inhibitors compared with levodopa as initial treatment for Parkinson's disease (PD MED): a large, open-label, pragmatic randomised trial. Lancet 2014;384:1196-205.

17 Weintraub D, Koester J, Potenza MN et al. Impulse control disorders in Parkinson disease: a cross-sectional study of 3090 patients. Arch Neurol 2010;67:589-95.

18 Corvol JC, Artaud F, Cormier-Dequaire F et al. Longitudinal analysis of impulse control disorders in Parkinson disease. Neurology 2018;91:e189-201.

19 Chou KL, Stacy M, Simuni T et al. The spectrum of "off" in Parkinson's disease: What have we learned over 40 years? Parkinsonism Relat Disord 2018;51:9-16.

20 Ferreira JJ, Lees A, Rocha JF et al. Opicapone as an adjunct to levodopa in patients with Parkinson's disease and end-of-dose motor fluctuations: a randomised, double-blind, controlled trial. Lancet Neurol 2016;15:154-65.

21 Borgohain R, Szasz J, Stanzione P et al. Two-year, randomized, controlled study of safinamide as add-on to levodopa in mid to late Parkinson's disease. Mov Disord 2014;29:1273-80.

22 Katzenschlager R, Poewe W, Rascol O et al. Apomorphine subcutaneous infusion in patients with Parkinson's disease with persistent motor fluctuations (TOLEDO): a multicentre, double-blind, randomised, placebo-controlled trial. Lancet Neurol 2018;17:749-59.

23 Schuepbach WM, Rau J, Knudsen K et al. Neurostimulation for Parkinson's disease with early motor complications. N Engl J Med 2013;368:610-22.

24 Castrioto A, Lozano AM, Poon YY et al. Ten-year outcome of subthalamic stimulation in Parkinson disease: a blinded evaluation. Arch Neurol 2011;68:1550-6.

25 Olanow CW, Kieburtz K, Odin P et al. Continuous intrajejunal infusion of levodopa-carbidopa intestinal gel for patients with advanced Parkinson's disease: a randomised, controlled, doubleblind, double-dummy study. Lancet Neurol 2014;13:141-9.

26 Worth PF. When the going gets tough: how to select patients with Parkinson's disease for advanced therapies. Pract Neurol 2013;13:140-52.

27 Seppi K, Ray Chaudhuri K, Coelho M et al. Update on treatments for nonmotor symptoms of Parkinson's disease-an evidence-based medicine review. Mov Disord 2019;34:180-98.

28 van der Kolk NM, de Vries NM, Kessels RPC et al. Effectiveness of home-based and remotely supervised aerobic exercise in Parkinson's disease: a double-blind, randomised controlled trial. Lancet Neurol 2019;18:998-1008.

29 Alty J, Robson J, Duggan-Carter P, Jamieson S. What to do when people with Parkinson's disease cannot take their usual oral medications. Pract Neurol 2016;16:122-8.

Address for correspondence: Dr Christopher Kobylecki, Department of Neurology, Manchester Centre for Clinical Neurosciences, Salford Royal NHS Foundation Trust, Stott Lane, Salford M6 8HD, UK.

Email: christopher.kobylecki@manchester.ac.uk 